\title{
Editorial
}

\section{Open Access and the Library}

\author{
Anja Oberländer ${ }^{1}\left(\mathbb{D}\right.$ and Torsten Reimer ${ }^{2, *}$ (i) \\ 1 Head of Open Science at the University of Konstanz, Universitaetsstrasse 10, 78457 Konstanz, Germany; \\ Anja.Oberlaender@uni-konstanz.de \\ 2 Head of Research Services at the British Library, 96 Euston Road, London NW1 2DB, UK \\ * Correspondence: Torsten.Reimer@bl.uk
}

Received: 24 December 2018; Accepted: 7 January 2019; Published: 9 January 2019

Libraries are places of learning and knowledge creation. While this mission has been the same for centuries, the way it is delivered is constantly evolving. Over the last two decades, digital technology - and the changes that came with it-have accelerated this transformation to a point where evolution starts to become a revolution.

The wider Open Science movement, and Open Access in particular, is one of these changes, and it is already having a profound impact. Under the subscription model, the role of libraries was to buy or license content on behalf of their users and then act as gatekeepers to regulate access on behalf of rights holders. In a world where all research is open, the role of the library is shifting from licensing and disseminating to facilitating and supporting the publishing process itself.

This requires a fundamental shift in terms of structures, tasks and skills. It also changes the idea of a library's collection. Under the subscription model, contemporary collections largely equal content bought from publishers. Under an open model, the collection is more likely to be the content created by the users of the library (researchers, staff, students etc.), content that is now curated by the library. Instead of selecting external content, libraries have to understand the content created by their own users and help them to make it publicly available - be it through a local repository, payment of article processing charges or through advice and guidance. Arguably this is an overly simplified model and it leaves aside special collections and other areas. Even so, it highlights the changes that research libraries are undergoing, changes that are likely to accelerate due to initiatives like Plan S.

This special issue investigates some of the changes in today's library services that relate to open access.

The shift of focus from procuring scholarly content to becoming a partner in creation and dissemination is shown in an article by Taylor and Jensen. They show how the University of Huddersfield has developed an open University Press to meet the increasing demand for demonstrating research impact [1]. Dealing with the problem that many researchers are in favor of open access but do not deposit in repositories due to various reasons, Daoutis and Montserrat Rodriguez-Marquez discuss the benefits of a mediated deposit approach, such as the one used by the University of Surrey [2]. An article by Walters and Daley shows how data from open science services can be used to enhance publication records [3].

New services require new structures and put new demands on library staff. The article by Bass and Slowe shows how new roles are implemented at the University of Kent through a hybrid matrix working model [4]. The University of Göttingen goes a different way of implementing and fostering open science - through a collaboration with several campus units and a wide range of activities and projects [5].

Two articles in the special issue deal with the financial side of Open Access. Colleagues from the research library in Jülich present a data-driven approach to budget control for both subscription and publication expenditure as an opportunity to enable the shift from one to the other, alongside the establishment of an Open Access Monitor [6,7]. Kohls and Mele describe the conversion of 
a whole scientific field (High Energy Physics) to open access via an international consortium of supporting institutions [8]. A different perspective is given by authors from the Federal Institute for Vocational Education and Training, who analyze the technical, structural and policy-related conditions of academic research in the context of open access use [9]. Finally, Revez' review article argues that through enhanced research support services, libraries can play a role to sustain an open path for knowledge production [10].

Together, these contributions highlight several facets of the changes research libraries are undergoing, and they set the scene for an ongoing transformation of library services. With growing international support for Plan S, a transition to a full open access publishing model (at least for articles) now looks closer than ever before. Research libraries should not just follow this process but closely shape it, as well-this requires ongoing reflection of and research into our own role.

Author Contributions: Conceptualization, A.O. and T.R.; Writing-Original Draft Preparation, A.O. and T.R.; Writing-Review \& Editing, A.O. and T.R.

Funding: This research received no external funding.

Conflicts of Interest: The authors declare no conflict of interest.

\section{References}

1. Taylor, M.; Jensen, K.S.H. Engaging and Supporting a University Press Scholarly Community. Publications 2018, 6, 13. [CrossRef]

2. Daoutis, C.A.; Rodriguez-Marquez, M.M. Library-Mediated Deposit: A Gift to Researchers or a Curse on Open Access? Reflections from the Case of Surrey. Publications 2018, 6, 20. [CrossRef]

3. Walters, D.; Daley, C. Enhancing Institutional Publication Data Using Emergent Open Science Services. Publications 2018, 6, 23. [CrossRef]

4. Bass, R.; Slowe, S. Supporting Open Access at Kent-New Staff Roles. Publications 2018, 6, 17. [CrossRef]

5. Schmidt, B.; Bertino, A.; Beucke, D.; Brinken, H.; Jahn, N.; Matthias, L.; Mimkes, J.; Müller, K.; Orth, A.; Bargheer, M. Open Science Support as a Portfolio of Services and Projects: From Awareness to Engagement. Publications 2018, 6, 27. [CrossRef]

6. Barbers, I.; Kalinna, N.; Mittermaier, B. Data-Driven Transition: Joint Reporting of Subscription Expenditure and Publication Costs. Publications 2018, 6, 19. [CrossRef]

7. Arndt, T.; Frick, C. Getting Scientists Ready for Open Access: The Approaches of Forschungszentrum Jülich. Publications 2018, 6, 24. [CrossRef]

8. Kohls, A.; Mele, S. Converting the Literature of a Scientific Field to Open Access through Global Collaboration: The Experience of SCOAP3 in Particle Physics. Publications 2018, 6, 15. [CrossRef]

9. Langenkamp, K.; Rödel, B.; Taufenbach, K.; Weiland, M. Open Access in Vocational Education and Training Research. Publications 2018, 6, 29. [CrossRef]

10. Revez, J. Opening the Heart of Science: A Review of the Changing Roles of Research Libraries. Publications 2018, 6, 9. [CrossRef]

(C) 2019 by the authors. Licensee MDPI, Basel, Switzerland. This article is an open access article distributed under the terms and conditions of the Creative Commons Attribution (CC BY) license (http://creativecommons.org/licenses/by/4.0/). 